\title{
Biogeography and Long-Run Economic Development ${ }^{*}$
}

\author{
by \\ Ola Olsson and Douglas A. Hibbs, Jr. \\ Department of Economics, \\ Göteborg University \\ Revised version for European Economic Review, \\ 13 May 2002
}

\begin{abstract}
The transition from a hunter-gatherer economy to agricultural production, which made possible the endogenous technological progress that ultimately led to the Industrial Revolution, is one of the most important events in thousands of years of humankind's economic development. In this paper we present theory and evidence showing that geographic and initial biogeographic conditions exerted decisive influence on the location and timing of transitions to sedentary agriculture, to complex social organization and, eventually, to modern industrial production. Evidence from a large cross-section of countries indicates that the effects of geography and biogeography on contemporary levels of economic development are remarkably strong.
\end{abstract}

Keywords: geography, biogeography and growth; economic development; agricultural revolution; institutions and growth; plants, animals and growth; Jared Diamond.

JEL Codes: N10; N50; O10; O41

* Address: Vasagatan 1, Box 640, 40530 Göteborg, Sweden. E-mail: ola.olsson@economics.gu.se, dhibbs@economics.gu.se 


\section{Introduction ${ }^{1}$}

During recent years, there has been an increasing awareness that geography affects economic development and growth. For instance, temperature, disease environment, and conditions for transport have been shown to influence agricultural productivity directly (Bloom and Sachs, 1998; Sachs 2001). Geographical factors are also believed to have played an indirect role by setting the basic conditions in which social institutions are formed (Acemoglu et al, 2001) and by defining environmental constraints to population growth (Kremer, 1993; Galor and Weil, 2000).

The argument made in this paper is that biogeography had a fundamental impact on economic development already in prehistory. Favorable biogeographic initial conditions - in particular the prevalence of plants and animals suited to domestication -expedited the transition from hunter-gatherer to sedentary agriculture in advantaged areas, leading to the rise of early "civilization" and conferring a development head start of thousands of years over areas less well endowed. In our model of long-run economic development, we show that the impact of this head start should still be detectable in the contemporary international distribution of prosperity. Empirical evidence from a large cross-section of countries supports this hypothesis.

The notion that geography broadly conceived matters for societal development is not new. At least as early as the eighteenth century Montesquieu (1750) advanced a theory featuring the political influence of climate. In more recent studies of the links between geography and economic development, one regularity always stands out: The majority of poor countries in today's world are found in the tropical climate zone; near the equator (Sala-i-Martin, 1997; Hall and Jones, 1999; Sachs, 2001). Among the factors believed to hamper agricultural productivity and development in the tropics are severe heat, discontinuous water supply and debilitating diseases (Landes, 1998), poor photosynthetic potential for annual plants (Bloom and Sachs, 1998), the absence of winter frosts that kill harmful organisms (Masters and McMillan, 2001), and (in Africa) deficient natural conditions for transport (Gallup et al, 1999).

Some recent work has focused on geography's indirect influence on today's levels of development through its impact on patterns of colonialism. Acemoglu et al (2001) argue that

\footnotetext{
${ }^{1}$ We thank Wlodek Bursztyn, Jared Diamond, Oded Galor, David Weil, Fabrizio Zilibotti, seminar and conference participants at Copenhagen University, Göteborg University, Oslo University, University of Vienna, the European and US Public Choice Societies, the Population and Economic Growth Workshop at Brown University, the UCLA Tuesday Political Economy lunch (especially Edward Leamer, and Miriam Golden who supplied a written report of reactions) and a referee and editor of this journal for useful comments, not all of which we chose to act upon. The authors gratefully acknowledge financial support from Jan Wallander and Tom Hedelius' Stiftelse, HSFR grant F0382/97, and Adlerbertska Forskningsfonden.
} 
climate and the associated prevalence of mortal diseases affected decisively where colonizers from the Western world decided to create permanent settlements. In regions with high mortality rates "extractive institutions" were built, whereas durable settlements with good institutions typically were installed in colonies with a temperate climate, such as North America, Australia and New Zealand. In a paper that appeared as this one was undergoing the final edit, Easterly and Levine (2002) attempt to determine empirically whether the "geography hypothesis" of a direct influence on development, or the "institutions hypothesis" of an indirect effect of geography via institutions, has better explanatory power. They conclude that geography's effects are indirect, running entirely through institutional development, which supports the general line of argument in Acemoglu et al (2001).

However, whereas Acemoglu et al start their analysis at the onset of colonization around 1500 A.D., we contend that a more defining historical era - the one that ultimately gave Europe the ability to colonize the rest of the world - is the period of the Neolithic revolution, some 10,000 years ago. This fundamental shift in economic production and associated living conditions has not often been analyzed by economists. Early attempts at establishing analytical frameworks with some focus on property rights were provided by Smith (1975) and North (1981, chap 7). Drawing on a large archaeological and anthropological literature, Morand (2001) uses a Nash bargaining set-up to model the transition from hunting-gathering to settled agriculture, and then from agriculture to industrial production. As one of the primary reasons for the first transition, Morand identifies climatic stress at the end of the Pleistocene era in combination with some groups' confinement to oases of relative affluence, surrounded by desert-like environments.

Our research is also related to long-run models of development that focus on the relationships between population and economic development in a Malthusian tradition. Galor and Weil (2000) model the transition from a Malthusian regime - when technological progress is slow and population growth is small - to a Modern Growth regime when growth rates are high and population growth small or negative. The key factor behind this change according to Galor and Weil is that technological progress eventually creates a disequilibrium that induces parents to switch from "child quantity" to "child quality" (education). Geography plays a role in the background since the (fixed) quantity and quality of land might affect the timing of the escape from the Malthusian regime. ${ }^{2}$ In an attempt to synthesize Malthusian analysis and the population theory of Boserup (1965), Kremer (1993) presents a long-run model of development

\footnotetext{
${ }^{2}$ Other contributions modeling the transition out of a Malthusian regime includes Hansen and Prescott (1999), Lagerlöf (2000), Kögel and Prskawetz (2001) and Galor and Moav (2002).
} 
where the driving force is a feedback process between levels of population and technological progress. All else equal, continents with a greater land mass should have a faster population growth and a more rapid technological progress than smaller regions, a hypothesis that Kremer finds to be broadly consistent with the historical record. ${ }^{3}$

This article shares Galor and Weil's distinction between a Malthusian and a post-Malthusian era. However, although standards of living do not increase in our model until the Industrial Revolution, it is the agricultural revolution in early Neolithic times that introduces the crucial process of endogenous knowledge creation that drives civilizations toward the Industrial Revolution.

A general biogeographic framework for explaining the dominance of the Western world is presented in a remarkable book by Jared Diamond (1997). Diamond argues that the enormous size of the Eurasian continent, its large Mediterranean zone in the western part and the EastWest orientation of its major axis, meant that Eurasia was disproportionately endowed with plants suited to cultivation, animals suited to domestication, and natural corridors of transit and communication suited to the diffusion of innovations. Because of these biogeographic advantages, the agricultural revolution occurred earlier in Eurasia than anywhere else. The surplus generated by the superior agricultural mode of production made possible the establishment of a non-producing class whose members were crucial for the rapid development of writing, science, cities, technology-based military prowess and formation of states. When the continents finally collided in the late fifteenth century, the crops, horses, knowledge, institutions, weapons, and animal-based germs that had evolved in Eurasia over thousands of years overwhelmed the indigenous communities of the Americas, Africa, and Australia.

The model presented in this article builds upon Diamond's sweeping study ${ }^{4}$ by proposing fundamental links between initial biogeographic conditions and subsequent economic development; links so powerful that their consequences are today still be detectable in international variations in output and productivity. Societies enjoying biogeographic environments with great productive potential were the first to experience an agricultural revolution making possible the development of a non-food producing sector of political and administrative elites that created and organized knowledge. After the transition from hunting and gathering to sedentary agriculture, economies enter a path of endogenous technological

\footnotetext{
${ }^{3}$ For articles in the Kremer tradition, see Goodfriend and McDermott (1995) and Jones (2001).

${ }^{4}$ Some of Diamond's ideas were anticipated in less comprehensive and global scale by the work of the eminent archaeologist and pre-historian Professor Lord Colin Renfrew of Cambridge University. Renfrew's scholarship focuses on Indo-European cultural-linguistic diffusion, absorption and domination at the Neolithic transition, rather than on development per se, as here and in Diamond (1997). See, for example, Renfrew (1992), (1993), (1996).
} 
progress and increased population growth. Per capita output, however, does not start growing until the Industrial Revolution when the Malthusian link between rising output and population is broken. The model predicts that, all else equal, regions that made the transition to agriculture early also will be the first to develop industrial production. The central hypothesis we investigate quantitatively is that present levels of per capita income still register the effects of initial condition biogeography. This hypothesis receives strong empirical support in data for a large cross-section of countries.

We claim to make at least three contributions in this article. First, along with North (1981), Morand (2001), and a few other articles, it is among the only attempts to explain the Neolithic transition from hunting-gathering to agriculture; a crucial event in world history which economists have largely overlooked. Second, unlike previous studies, we present a formalized theory in the spirit of Diamond (1997) of the causal links between biogeographic endowment, the emergence of agriculture, and current levels of prosperity. Lastly, unlike any other research on long run growth that we are aware of, this article confronts the theory with biogeographical data.

The outline of the rest of this paper is as follows. Section two reviews modern archaeological evidence on the emergence of horticulture and animal husbandry ("sedentary agriculture"). Section three develops a stylized theoretical framework showing how initial biogeographic conditions affected the timing of transitions thousands of years ago from huntergatherer to agricultural production, thereby unleashing sustained technological progress that eventually led to the Industrial Revolution. Section four supplies empirical evidence on the model's principal implications regarding the importance of geography and biogeography to economic development. Section five concludes by summarizing the theory and evidence featured in our research.

\section{The Agricultural Revolution}

Around 11,000 B.C. humankind was on the verge of entering an era of yet to be surpassed economic development. The retreat of the great glaciers that marked the end of the Pleistocene geological epoch and the beginning of the Holocene, brought a warmer and wetter climate and a reoccupation of the ecological vacuum that the ices had left. Modern Cro-Magnon humans capable of marvelous cave paintings and equipped with standardized stone tools and sewn clothing - had by this time populated all the major continents on earth. As noted by Diamond 
(1997, p 52) “....an observer transported back to 11,000 B.C. could not have predicted on which continent human societies would develop most quickly, but could have made a strong case for any of the continents." ${ }^{, 5}$ Nevertheless, with hindsight we know that the paths to sedentary agriculture were radically different across continents.

It turned out that the transition from a hunter-gatherer lifestyle to sedentary agriculture, based on domesticated plants and animals, first occurred in the so called Fertile Crescent of the Near East, encompassing the present-day countries Israel, Lebanon, Syria, Jordan and Iraq. ${ }^{6}$ By 8500 B.C. the first signs of domesticated barley, emmer, and einkorn wheat appeared in the Jordan Valley and in the Southern Levant. Within the following thousand years agricultural development in the Fertile Crescent continued with the domestication of goat, sheep, pig, and, somewhat later, cattle. The new form of economic life created a rising population density, new demands on social organization, and a food surplus that could be used to feed a non-producing class of chiefs, priests, warriors, and bureaucrats. About 4,500 years after the initial steps toward agriculture, the first modern civilization with writing, science, religion, cities and states, emerged in the river valleys of Tigris and Euphrates. The change from hunting and gathering to sedentary agriculture would forever alter human life and activate a radically new path of rapid development along which we are still traveling.

As Table 1 shows, the Near East was not the only center of independent domestication of plants and animals. China (or possibly Central Mexico) was the next area to develop an agricultural system that was dependent on rice and millet cultivation and domesticated pigs. As for China, it is probable that the domestication of rice took place in the South along the Yangtze River, while millet was introduced in the North along the Yellow River. The agricultural practices of Central Mexico did not spread south of the tropical rain forests. Hunter-gatherers in the Andes and Amazonian lowlands independently created food production based on potato, manioc, and llamas. New research has found that plants were domesticated also in Eastern United states around 2500 B.C., whereas independently developed agriculture can be traced back to around 4000 B.C. in Sub-Saharan Africa. There are, however, other possible candidates.

\footnotetext{
${ }^{5}$ Why start the analysis 11,000 B.C. rather than 100,000 B.C. or even one million years ago? There are at least five reasons. First, the Cro-Magnon human race is only 100,000-200,000 years old and migrated out of Africa around 50,000 years ago. Second, the retreat of the glaciers started after 18,000 B.C. and climate did not allow agriculture based on domesticated plants until the end of the Pleistocene. Third, all of the major continents were not populated until approximately 11,000 B.C. Fourth, technologies for harvesting, transporting, preparing, and storing cereals were not in place until the date in question. Fifth, before 11,000 B.C. there are no clear signs of unequal levels of development between regions (Diamond, 1997).

${ }^{6}$ Domestication of a species is defined as "...the human creation of a new plant or animal - one that is identifiably different from its wild ancestors and extant wild relatives.../and which/...has been changed so much that it has lost its ability to survive in the wild." (Smith, 1998, p 18-19).
} 
Claims are sometimes made that Ethiopia and New Guinea might have domesticated plants, while cattle might have been independently domesticated in India.

Table 1: Independent Origins of Sedentary Agriculture

\begin{tabular}{llll} 
Area & Date & Domesticated Plants & Domesticated Animals \\
\hline 1. Near East & 8500 B.C. & wheat, barley, pea & goats, sheep \\
2. China & 7500 B.C. & rice, millet & pig \\
3. Central Mexico & 3500 B.C. & corn, beans & turkey \\
& $(8000$ B.C. $)$ & & \\
4. South Central Andes / & 3500 B.C. & potato, manioc & llama, guinea pig \\
Amazonian lowlands & (5800 B.C. $)$ & & \\
5. Eastern United States & 2500 B.C. & sunflower & none \\
& $(3200$ B.C. $)$ & & none \\
6. Sub-Saharan Africa & 4000 B.C. & sorghum &
\end{tabular}

Notes: Dates refer to the first attested date of domestication of an animal or plant. All dates here and elsewhere in the text are calibrated radiocarbon dates. The dates of the three American regions are from Diamond (1997). Due to uncertainty about these dates, Smith's (1998) much earlier approximations are shown in parentheses. The domesticated plants and animals in the right hand side columns are examples, rather than a complete listing, of domesticated species in the area.

Source: Diamond (1997, p 100) and Smith (1998, p 13).

How, then, did the agricultural revolution occur? What was it that prompted huntergatherers to abandon a nomadic life-style and undertake domestication of plants and animals? These issues have been intensely debated for decades within the scientific community. There are at least four broad theories of the reasons behind the agricultural transition: ${ }^{7}$ (i) The domestication of plants and animals occurred as a reaction to environmental conditions (Childe, 1935; Diamond, 1997). (ii) It occurred as a response to exogenous population pressure (Boserup, 1965; Cohen, 1977). (iii) It occurred because of a culturally innate desire to civilize nature (Fernandez-Armesto, 2000). (iv) It was the result of a more or less unintended evolutionary adaptation by some species with an unusually high potential (Smith, 1998; Diamond, 1997). Out of these, the population and cultural theories (ii and iii) have not received much support in the archaeological literature (Harlan, 1995). In this article, we will focus in particular on environmental reasons for the transition and on the influence of unintended but beneficial evolutionary effects.

\footnotetext{
${ }^{7}$ See Olsson (2001) for a survey of the literature and a model that incorporates all four reasons behind the agricultural transition.
} 
In what is probably the most comprehensive survey of modern research on the subject, Smith (1998) identifies a number of factors that the independent transitions to agriculture in the Levant, in the Southern Sahara and in the Eastern United States had in common. First, in all three regions, the species brought under domestication were seed plants rather than root crops or animals. Second, in all three regions, the wild ancestors of these domesticates appear to have been important food sources before their domestication. Third, the people who domesticated these seed plants lived in relatively large, permanent communities occupied throughout most, if not all, of the year. Fourth, these societies were relatively affluent, having access to a broad spectrum of wild plants and animals in their diets, as well as to the resources of rich aquatic habitats. Fifth, since these early agricultural settlements were located near lakes or rivers, they also had access to a reliable supply of groundwater. Sixth, it appears that the agricultural communities were bounded in time and space by less secure environments. Preceding the emergence of agriculture in all three regions were climatic changes that worsened the conditions for the hunter-gatherer way of living in the areas surrounding the richer environments near lakes and rivers.

It is important to stress, however, that the emergence of food production was far from a deliberate revolution in human lifestyle. Diamond (1997) describes vividly how the first stands of domesticated wheat in the Fertile Crescent probably appeared near latrines, garbage heaps, forest paths and cooking-places where humans unintentionally had disseminated seeds from their favorite wild grasses, growing nearby. More conscious experimentation was presumably then carried out in the fertile riverbank soils on the outskirts of the villages by people whose relative affluence gave them time for such risky activities. Furthermore, by 11,000 B.C, all the necessary technological prerequisites were in place in the Fertile Crescent for an agricultural lifestyle; flint blades in wooden handles for cutting grass, baskets, mortars, and the techniques for roasting grains and storing food underground.

A key issue is whether the agricultural revolution took place out of necessity or because of opportunity. In the language of the economics of innovation, was the emergence of agriculture a result of "demand-pull” or "supply-push"? Advocates of the former view argue that a temporary climatic downturn around 9500 B.C. -- often referred to as "the Younger Dryas" -- in combination with the sudden extinction of many big mammals, might have forced huntergatherers into a few oases where a closer interaction between man and nature led to the domestication of plants and animals (Childe, 1935). However, as the comparison by Smith (1998) above shows, rather than being societies sorely in need of a more efficient way of living, the first agriculturists appear to have belonged to relatively prosperous groups who possessed 
the technology, time, and energy to conduct experimental search for ways of reducing long-term risk. Observing the immediate and impressive gains from such experiments, a transition then followed within a relatively short span of time.

Could the stunning success of the hunter-gatherers' agricultural experiments in the Fertile Crescent be explained by their extraordinary capacity to exploit their environment - a capacity greater than, for instance, that of the last remaining hunter-gatherers in New Guinea? Diamond (1997) convincingly refutes this argument. Having lived among hunter-gatherers in New Guinea, he describes these native New Guineans as "walking encyclopedias" with detailed knowledge of every imaginable use that could be made of hundreds of plants and animals. This profound knowledge of the natural environment, gained through thousands of years of observation, has also been recorded among other primitive peoples. The notion that native New Guineans or Aboriginals perhaps might have "missed" some crops or animals that could have been successfully domesticated therefore seems highly unlikely. Furthermore, when for example cattle spread south of the Sahara, hunter-gatherers there quickly adopted a pastoral lifestyle. When horses were introduced in North and South America, native inhabitants immediately developed great skills in using them. Indeed, there is no reason to believe that hunter-gatherers in some locales had greater inherent ability to domesticate plants and animals or otherwise to exploit fully the potential of their environment, than hunter-gatherers in other areas.

A crucial element for the success of agricultural experiments is rather to have good material to work with. With no suitable species naturally available for domestication, there can be no fruitful experimentation and no agriculture. In his careful taxonomy of wild plants and animals suitable for domestication, Diamond (1997) demonstrates that the distribution of such species is very uneven across continents. Out of about 200,000 wild plant species in the world, only a few thousand are edible, and just a few hundred have ever been domesticated. In a compilation by Blumler (1992) of the 56 heaviest-seeded wild grasses on earth - that is, the most obvious candidates for plant domestication - it is demonstrated that as many as 33 grow naturally somewhere in the Western part of Eurasia, predominantly in the Mediterranean areas of the Near East. (See Table 2.) Six species are confined to Eastern Asia, whereas only two grow in Australia and South America.

The pattern is roughly the same for animals. The animals most suited to domestication are big, terrestrial, herbivorous mammals. Out of 148 species of such mammals weighing more than 45 kilos, only 14 ever have been domesticated. The remaining 134 have all proven impossible to domesticate for various reasons; they are inherently too nasty, they have a tendency to panic, 
they do not breed in captivity, they have a maturation rate that is too slow, or they do not have the required dominance hierarchy in their social structure that humans can use to gain control. Only 14 big mammals were not disqualified on the grounds above, and as many as 9 of these were found in the Near East, among them "the big four": The wild ancestors of goat, sheep, pig, and cattle. Contrast this with South America's single suitable species (the llama) and the total lack of suitable species in North and Central America, Australia, and Sub-Saharan Africa. The Sub-Saharan case is particularly sad because the region has as many as 51 of the 148 heaviest mammals on earth, but not a single one passed the audition for domestication.

Table 2 shows that Western Eurasia in particular, but also East Asia, had superior initial biogeographic conditions for agricultural experimentation. Why was this the case? The answer lies in the continent's geography and climate. First, Eurasia is by far the largest landmass on the planet and it is naturally endowed with the greatest variation of species. Second, the early success of food production in the Fertile Crescent, and its rapid diffusion to Europe and North Africa, can largely be explained by its Mediterranean climate. All the major crops cultivated in the Fertile Crescent were annual grasses. As shown by Blumler (1992) and others, a Mediterranean climate with wet winters and dry summers is particularly favorable for annual grasses. There are Mediterranean zones also in other parts of the world - in Chile, South Africa, Southern California, and Northern Australia - but none of these were nearly as big as the Eurasian zone. Although wet tropical habitats typically show an enormous biological diversity, their lack of seasonal changes, the irregularity of water supply, the relatively poor quality of soils, and the prevalence of diseases and pests harmful to humans, animals and crops, make agriculture problematic (Kamarck, 1976).

A third important reason, emphasized by Diamond (1997), is the East-West orientation of Eurasia's major axis. An East-West axis orientation facilitates diffusion of plants and animals. There are a number of reasons for this: Along the same latitude, regions will typically have the same day length, the same seasonal variations, the same regimes of temperature and rainfall, and even the same diseases. Imported domesticated species can easily adapt to such similar environments even though their wild ancestors live elsewhere. All other continents have NorthSouth as the main axis of orientation, and this hampered the diffusion of agricultural innovations.

A picture thus emerges of opportunity rather than need as being the prime causal factor tipping development in favor of agriculture in certain areas. The advantages would soon become obvious; domesticated plants gave a reliable source of food with high nutritional value that could feed a much greater population per unit area than hunting-gathering. Domesticated 
animals gave meat, milk, fertilization, wool, leather, and were subsequently used for transport, plowing, and warfare. The close physical proximity of man and animal also eventually gave agriculturists a high resistance to animal related germs such as those causing smallpox, measles, and tuberculosis. All these advantages gradually made organized food production the dominant way of living in all of Eurasia where expanding agricultural communities swept away most of the remaining hunter-gatherers.

Table 2: Distribution of Species Suitable for Domestication

\begin{tabular}{|c|c|}
\hline Area $^{a}$ & $\begin{array}{c}\text { Number of } \\
\text { Plants }^{\mathrm{b}}\end{array}$ \\
\hline
\end{tabular}

\begin{tabular}{lcc} 
& Plants $^{\mathrm{b}}$ & Animals $^{\mathrm{c}}$ \\
\hline Near East, Europe, North Africa & 33 & 9 \\
East Asia & 6 & 7 \\
Southeast Asia & 6 & 2 \\
Sub-Saharan Africa & 4 & 0 \\
North America & 4 & 0 \\
Central America & 5 & 0 \\
South America & 2 & 1 \\
Australia & 2 & 0 \\
Pacific Islands and Iceland & 0 & 0 \\
\hline
\end{tabular}

\footnotetext{
${ }^{a}$ The division of Eurasia into three subcontinents is made since food production systems evolved independently and with very different features in the East and West with arid Central Asia as a barrier between them. Early agriculture in the Near East spread to Europe and North Africa but not to Sub-Saharan Africa. Diffusion also took place from China to Southeast Asia, but due to the tropical climate in Southeast Asia, a different set of species was used there. Because of the north-south axis, diffusion of plants and animals was limited between the Northern, Central, and Southern parts of America.

${ }^{b}$ The numbers refer to the geographical distribution of the world's 56 heaviest wild grasses (Blumler, 1992). The figures do not add to 56 because some species are found in more than one continent.

c The numbers refer to the geographical distribution of the world's 14 domesticable herbivorous or omnivorous, terrestrial mammals weighing more than 45 kilos (Nowak, 1991; Diamond, 1997).

Sources: Nowak (1991), Blumler (1992), and Diamond (1997).
}

The path to what is usually referred to as "civilization" was now open. In densely populated towns and cities, a nonproducing class emerged which was able to dominate the rest of the population by gaining control of the agricultural surplus. Among these classes of chiefs, priests, warriors, bureaucrats, and skilled craftsmen, an explosion of new knowledge occurred in astronomy, mathematics, geometry, construction, and social organization. Writing, probably the 
most important innovation of all times, first appeared in Sumer around 4,000 B.C. Great empires soon emerged; Akkad, Egypt, Assyria, Babylon, Persia, and the most advanced of them all, the Greek and Roman civilizations, which today still serve as the pillars of Western civilization. Meanwhile, in less well-endowed areas like Sub-Saharan Africa and Australia areas with hardly any domesticable species - development was much slower. Agriculture was eventually adopted in Sub-Saharan Africa through the expansion of the Bantu peoples, but when the Europeans finally arrived in Australia, they found an Aboriginal population that was still at the hunter-gatherer stage of development. Judging from the data in Table 2 and from the argument developed above, this was not at all surprising.

\section{A Theoretical Framework}

In this section, we present a simple theoretical framework of economic development over the three major stages of history; the hunter-gatherer stage, the agricultural stage, and the industrial stage. ${ }^{8}$ The aim is to provide a formal representation of the link between initial biogeographic conditions and the present level of economic well-being. We make use of four stylized facts which were derived in the previous section: (i) Agriculture was first developed in relatively rich environments. (ii) There were no differences across continents in huntergatherers' inherent ability to exploit their natural environments. (iii) The agricultural revolution made possible the emergence of a class of chiefs, craftsmen, and bureaucrats that lived on the surplus from the food producing sector. (iv) The emergence a non-food-producing class initiated a process of endogenous knowledge creation that increased aggregate output and population. In addition to these four stylized facts, we introduce a fifth, derived from the empirical literature on long run growth: (v) Standards of living (output per person) did not significantly increase until the Industrial Revolution (Maddison, 1982; Fogel, 1999; Johnson, 2000).

The basic intuition behind the model is that regions with a favorable biogeography experience the agricultural revolution early and enter the path of endogenous knowledge creation. Due to their head start, these regions are also the first to experience the Industrial

\footnotetext{
${ }^{8}$ The model in Galor and Weil (2000) also has three fundamental stages, but those below do not fully correspond to Galor and Weil's Malthusian, post-Malthusian and Modern regimes. The Malthusian regime would encompass both the hunting-gathering and agricultural stages.
} 
Revolution, whereupon income per capita finally starts growing. Hence, all else equal, the better the initial biogeographic endowment, the greater the current level of income per capita.

\subsection{Initial Biogeographic Endowments}

As discussed in the previous section, the date 11,000 B.C. appears to be a good starting point for an analysis of the transition from primitive to modern production. All major continents had been populated and technologies for collecting, processing and storing food were widely known (Diamond, 1997). We shall assume that by this time there are $N$ variations of geographic conditions and biogeographic endowments in those parts of the world that were settled by human beings. Such environments would include tropical rainforests, arctic tundra, lowland deserts, Mediterranean grasslands, and so on.

For simplicity, we imagine that all environments are stable over time, even though environmental conditions went through changes during the Holocene geological epoch. The tremendous increase in rainfall in the wake of retreating ice caps -- which for instance temporarily made possible permanent hunter-gatherer presence in the Sahara -- eventually reached a peak and was followed by cooler and drier periods. Although such changing conditions surely affected human life, they did not change the fundamental character of a particular environment relative to other environments; even if the Sahara temporarily had higher precipitation, it was still a tropical dry region in the north of the African continent which lacked suitable species for domestication.

We further assume that with each variation $n=\{1,2, \ldots N\}$ in the natural conditions of early human life there is associated a biogeographic productive potential $\tilde{A}_{n}$, where $\tilde{A}_{n}$ is a positive real number. This variable reflects the number of plants and animals suited to domestication under conditions $n$. It is the maximum number of species that non-agriculturists in $n$ could possibly domesticate for the production of food. As shown above, only a very small fraction of all plants and animals are edible, even in those environments that have the greatest variety of species. An even smaller fraction of species is domesticable. Hence, $\tilde{A}_{n}$ should be thought of as the quality of initial biogeography in $n$.

A crucial assumption in the model below is that the initial conditions for environment $n, \tilde{A_{n}}$,

are different from the initial conditions of all other environments, that is, $\tilde{A}_{n} \neq \tilde{A}_{n+1}$ for all $n=\{1,2, \ldots N\}$. This means that a ranking of the productive potentials is possible. The quality of 
$\tilde{A_{n}}$ in turn is determined by exogenous geographic conditions. Climate is an important factor in this regard. For various reasons, the biogeographic productive potential of Mediterranean habitats is greater than that of, for instance, arctic regions. In fact, as we pointed out in the previous section, the agricultural potential of the Mediterranean climate zone in Eurasia appears to be superior to all others. The size of the continent also influences $\tilde{A}_{n}$, as does the orientation of its major axis.

\subsection{The Hunter-Gatherer Economy}

In all three basic stages of development, output per capita is given by:

$$
y_{n}(t)=\frac{\delta(t) \cdot A_{n}(t) \cdot\left(v(t) \cdot L_{n}(t)\right)^{1-\alpha}}{L_{n}(t)}
$$

$\delta(t) \geq 1$ indicates the level of productivity at time $t \in[0, T], A_{n}(t)>0$ reflects the upper bound to a continuum of intermediate capital goods used in environment $n$ at time $t, v(t) \in(0,1]$ is the fraction of total population engaged in food production, $L_{n}(t)$ is total population (equal to the total labor force) in environment $n$ at time $t$, and $\alpha \in(0,1)$ is the output elasticity of capital. ${ }^{9}$ Although $A_{n}(t)$ formally defines the range of intermediate capital goods at $t$ including animals and plants, we will frequently refer to it (as in the endogenous growth literature) as the state of technology or knowledge. Note that whereas four variables in (1) vary over time, only $A_{n}(t)$ and $L_{n}(t)$ vary across environments.

There are three fundamental stages of economic development: The hunter-gatherer economy, sedentary agriculture, and modern industrial production. In the beginning and during the greater part of human history, all human beings across all environments were huntergatherers. The time span that we will consider is $[0, T]$ where 0 is the starting point of our analysis at approximately 11,000 B.C. and $T=13,000$ is the present day. At some point in time $t_{n}^{A} \in(0, T]$, the $n$-th economy makes the switch to full-scale agriculture. The hunting-gathering

\footnotetext{
${ }^{9}$ The function should be interpreted as a simplified form of the well-known product variety specification, used by for instance Romer (1990), such that $\int_{i=0}^{A_{n}(t)} x(i)^{\alpha} d i=A_{n}(t)$ where $x(i)$ is the quantity of an intermediate capital good of vintage $i, \alpha$ is the elasticity of intermediate goods, and $x(i)=1$ for all $i, n$ and $t$.
} 
era $\left[0, t_{n}^{A}\right]$ is a kind of transition period that is characterized by relatively mature subsistence strategies in comparison to the more primitive ones used in the millennia that preceded it. People start making more or less conscious efforts at transforming the environment to suit human needs (Harlan, 1995).

During the hunting-gathering stage, the variables in (1) assume the following values:

$$
y_{n}(t)=\underline{y}, \quad \delta(t)=1, \quad A_{n}(t) \in\left[1, \tilde{A}_{n}\right], \quad v(t)=1 \quad \text { at all } t \in\left[0, t_{n}^{A}\right] .
$$

Output per capita during the whole period and in all $n$ is constant at the subsistence level $\underline{y}$. Both the productivity variable $\delta$ and the sectoral allocation variable $v$ equal unity. The whole hunter-gatherer population is thus engaged in primitive food "production". The range of intermediate capital goods $A_{n}(t)$ should in this era be thought of as the number of plants and animals with a potential for domestication that have been incorporated in the subsistence economy of the hunter-gatherers. A continuum $A_{n}(t) \in\left[1, \tilde{A}_{n}\right]$ of useful wild species are known and exploited at each $t$. It is important to note that these species have still not been domesticated. The assumptions in (2) simplify the production function in (1) to become $\underline{y}=A_{n}(t) \cdot L_{n}(t)^{-\alpha}$.

An increase in $A_{n}(t)$ means that a new wild but not yet domesticated plant or animal has been added to the hunter-gatherer subsistence economy. Over time we assume that $A_{n}(t)$ grows according to a process $\dot{A}_{n} / A_{n}=f\left(\widetilde{A}_{n}\right)$. Growth in the knowledge of productive species might be thought of as random since hardly any resources are devoted to experimental research activities. The discovery of new suitable species is to a large extent a matter of luck or pure chance. However, disregarding all stochastic elements, the growth rate of the number of known productive species is

$$
\frac{\dot{A}_{n}}{A_{n}}=f\left(\tilde{A}_{n}\right)=\gamma \tilde{A}_{n}
$$

where $f^{\prime}\left(\tilde{A_{n}}\right)=\gamma>0$ is a parameter reflecting people's propensity to learn from nature. Equation (3) implies that the greater the biogeographic endowment of $n$, the greater its growth rate of productive knowledge. Note also the central assumption that $\gamma$ is constant across all $n$. In line 
with the stylized facts discussed above, this means that there are no differences between societies in inherent ability to learn about and exploit environments. Differences in the growth of productive knowledge derive solely from differences in initial conditions $\tilde{A}_{n}$, that is, there are simply more useful things to learn and more species to exploit in a richer environment.

The solution to the differential equation for $A_{n}(t)$ implied by (3) is

$$
A_{n}(t)=A(0) \cdot \exp \left(\gamma \tilde{A}_{n} t\right) \quad \text { at all } t \in\left[0, t_{n}^{A}\right]
$$

$A(0)$ is equal across all $n$ and is here normalized to be $A(0)=1$.

The agricultural revolution occurs when $A_{n}$ reaches a certain threshold value $A^{A}$. This threshold value reflects a critical number of exploited species that must be attained for the full transition to occur. More precisely, the agricultural revolution is complete when (i) people have become sedentary in permanent villages and (ii) some plant or animal has been domesticated, that is genetically differentiated from its wild ancestor. Neither of these conditions will be met unless a sufficiently large number of species with a high potential have been included in the hunter-gatherer subsistence economy. With too few useful species known or locally available, hunter-gatherers remain non-sedentary nomads. Non-sedentary hunter-gatherers do not have the opportunity to conduct systematic experiments on plants and animals. When the critical level is reached, hunter-gatherers settle down and start more systematic efforts at increasing the yields from their favorite plants. Domesticated species often emerged from this process surprisingly easily. $^{10}$

Like $\gamma$, we assume that $A^{A}$ is identical everywhere. Sedentary agriculture generally required at least one heavy, herbivorous, protein-rich mammal and two to three potential staple crops. ${ }^{11}$ The composition of these "founding species" can vary. In the Fertile Crescent, the food production package was based on the domesticated ancestors of sheep, goat, pig, cattle, emmer wheat, einkorn wheat, and barley, while in East Asia it included pigs, water buffalo, chicken, rice, foxtail millet, and soybean (Diamond, 1997; Smith, 1998).

One tragic reality of nature is that in some environments, $\tilde{A}_{n}<A^{A}$. An indigenous population could never inaugurate agriculture in such areas. When development has reached the

\footnotetext{
${ }^{10}$ For instance, a single gene mutation in emmer wheat is enough to prevent the stalks from shattering, a characteristic that greatly facilitates cultivation (Diamond, 1997).

${ }^{11}$ Jared Diamond pointed out to us that the historical record suggests that the presence of a heavy mammal greatly increased agricultural productivity but was not strictly necessary for the transition. to settled agriculture, eastern North America and Mexico being examples of exceptions.
} 
stage $A_{n}=\tilde{A}_{n}<A^{A}$, then $\dot{A}_{n} / A_{n}=0$. Without external shocks, such as colonization by people from richer environments, such societies are doomed to technological and economic stagnation. For instance, aboriginal Australians never passed the hunter-gatherer stage and the nearby Tasmanians even lost their once acquired ability to make stone tools (Kremer, 1993). A persuasive body of evidence suggests that the reason for this failure was the lack of suitable species for domestication (Diamond, 1997). The quality of initial conditions was inadequate. Hence, it is important to stress that agriculture does not inevitably emerge in our model.

Let us assume that society $n$ with $\tilde{A}_{n}>A^{A}$ attains the threshold level $A_{n}=A^{A}$ at time $t_{n}^{A}$. From (4) we then have that $A^{A} \equiv A_{n}\left(t_{n}^{A}\right)=\exp \left(\gamma \tilde{A}_{n} t_{n}^{A}\right)$. Taking logs and rearranging, we obtain an explicit expression for $t_{n}^{A}$ :

$$
t_{n}^{A}=\frac{\ln A^{A}}{\gamma \tilde{A}_{n}}=\frac{\kappa}{\tilde{A}_{n}}
$$

In (5) $\kappa$ is a positive constant that is identical across environments; $t_{n}^{A}$ thus depends only on $\tilde{A_{n}}$. To make things even clearer, let $T-t_{n}^{A}=T-\kappa / \tilde{A}_{n}$ be the number of years from the present back to the time at which agriculture was introduced; then it is easily shown that $\partial\left(T-t_{n}^{A}\right) /\left(\partial \tilde{A}_{n}\right)=\kappa / \tilde{A}_{n}{ }^{2}>0$ and $\partial^{2}\left(T-t_{n}^{A}\right) /\left(\partial \tilde{A}_{n}\right)^{2}=-2 \kappa / \tilde{A}_{n}{ }^{3}<0$. The number of years since the adoption of sedentary agriculture in environment $n$ is thus a positive concave function of $\tilde{A}_{n}$, implying that the greater the productive potential of $n$ afforded by biogeographic endowments, the earlier the transition out of hunter-gatherer production. This is a central prediction of the model. The concavity in $T-t_{n}^{A}$ further suggests that the positive impact of initial biogeographic conditions on years elapsed since the transition to agriculture should be decreasing with $\tilde{A}_{n}$. These implications are investigated empirically in section four.

Of the variables in (1), there remains to define the dynamic process generating the total population, $L_{n}(t)$. It is often argued that there is a link between technological advance and population. There are at least two reasons for such an assumption. First, more people means more potential innovators of nonrivalrous ideas (Kremer, 1993; Jones, 2001). Second, an increase in productive knowledge creates surpluses that allow an increased level of population in a Malthusian manner (Galor and Weil, 2000; Lagerlöf, 2000). 
The fundamental assumption in (3) is that technological advance before the appearance of sedentary agriculture is opportunity-driven, that is a function of the productive potential of the environment. We further believe that technological advance temporarily results in rising living standards, which in turn allow population increases that force back income per capita to subsistence level. We therefore have a Malthusian process such that

$$
\frac{\dot{L}_{n}(t)}{L_{n}(t)}=\frac{1}{\alpha} \cdot \frac{\dot{A}_{n}(t)}{A_{n}(t)}=\frac{\gamma \tilde{A}_{n}}{\alpha} .
$$

A straightforward implication of this assumption is that the growth rate of output per capita is zero, which is consistent with (2). In other words, the effects of technological progress are offset in a Malthusian adjustment process by (what for simplicity and without any significant loss of generality we take to be) instantaneous increases in population. Thus, equilibrium output per capita remains at subsistence level $\underline{y}$ during the hunter-gatherer era.

\subsection{The Agricultural Economy}

The greater efficiency of agricultural food production had major implications for the $n$-th economy. It allowed resources to be transferred to a separate knowledge producing sector, which in turn led to an increase in the growth rate of new knowledge. Although this process initially created surpluses and rising living standards, Malthusian forces soon led to a proportional increase in population which neutralized technological advance and kept per capita income levels at subsistence level. ${ }^{12}$ A more predictable supply of food with a higher nutritional value, in combination with the reduced need of continual migration, also contributed to increased fertility.

The establishment of a non-food sector in settled communities, whose members lived on the agricultural surplus, was nonetheless one of the most fundamental societal changes in human history that initiated a process of endogenous technological change. ${ }^{13}$ In this sector were the kings, the warriors, the bureaucrats, the priests, and the specialized craftsmen. Their activities

\footnotetext{
${ }^{12}$ The archaeological record suggests that standards of living were roughly the same in early agricultural societies and in hunter-gatherer communities (Cohen and Armelagos, 1984). See also Maddison (1982), DeLong (1998), Fogel (1999), and Johnson (2000) for long-run estimates that support this conjecture.

${ }^{13}$ The introduction of a knowledge creating elite in our model has similarities to Galor and Moav's (2002) emergence of a "quality-type" among humans that favored human capital accumulation rather than child quantity. The society that makes the transition first should also have an evolutionary advantage compared to other societies since its productivity is higher and its population greater.
} 
were a prerequisite for the gradual evolution of civilization. These elites coordinated labor and allocated resources. In doing so they also invented written language, mathematics, science, law and institutions for social control and governance. New knowledge was created more systematically. Old knowledge began to be recorded and codified. Specialists, for instance in heavy grasses, could develop a deeper understanding of their object of study by carrying out natural experiments and analyzing carefully the results over time. The reduction of risk in food production must also have had important consequences for people's way of thinking about their place in nature and about what it was possible for their community to achieve. The first states based on these developments were formed around 4000 B.C. in the river valley economies of Tigris and Euphrates.

The production function for the food-producing sector during the agricultural era $\left(t_{n}^{A}, t_{n}^{I R}\right]$ is a modified variant of the equation in (1). The time-varying variables now have the following values:

$$
y_{n}(t)=\underline{y}, \quad \delta(t)=\delta^{A}>1, \quad A_{n}(t)>A^{A}, \quad v(t)=v^{A}<1 \quad \text { at all } t \in\left(t_{n}^{A}, t_{n}^{I R}\right]
$$

Output per capita remains at subsistence level since population growth offsets technological progress in a Malthusian manner (see below). The domestication of plants and animals has resulted in a higher level of factor productivity than previously, $\delta^{A}>1 .{ }^{14}$ The surpluses from this increased productivity are partly used for establishing a separate non-food sector. The fraction of the labor force that has been freed for this sector, $\left(1-v^{A}\right)$, comprises a small societal elite of chiefs, bureaucrats, scientists, and specialized craftsmen. Being in control of the agricultural surplus, this elite controls the masses of small-scale farmers. ${ }^{15}$ Whereas $v^{A}=1$ would be the optimal solution in a short-sighted, egalitarian hunter-gatherer society driven by survival objectives, the social planners in the ruling elite of town-based agriculturists now have longer planning horizons and realize that investments in a knowledge producing sector are necessary in order to advance technology beyond the limits set by the environment. Improvements in technology also increase population, which enhances the military power and prestige of the ruling elite. During the greater part of history, however, $\left(1-v^{A}\right)$ was close to 0 .

\footnotetext{
${ }^{14}$ In evolutionary terms, one might describe this jump in productivity as a mutation, caused by human selection, that introduced genotypes of plants and animals more suited to human needs.

${ }^{15}$ It is well known that the societies of early civilizations like Sumer and Egypt were strictly hierarchical.
} 
For simplicity, we assume that $v^{A}$, once the transition has been made, is identical across environments.

The range of intermediate goods $A_{n}(t)$ now exceeds the threshold level $A^{A}$. However, it might also be the case that $A_{n}(t)>\tilde{A}_{n}$. The establishment of a nonproducing sector made it possible for the people in $n$ to learn about and create capital goods beyond the limit set by $n$ 's initial environmental conditions. Apart from sheep, cows and wheat, the farming communities now invest in town walls, irrigation systems, and public storehouses. In a hunter-gatherer society, such capital goods are useless, but in a relatively densely populated farming community, inventions like these are vital.

Growth in productive knowledge is described by the following simple function:

$$
\dot{A}_{n}(t)=A_{n}(t)\left(1-v^{A}\right)
$$

The rate of knowledge growth is therefore $\left(1-v^{A}\right)>0$. Since the ideas inherent in $A_{n}(t)$ are nonrivalrous, they can be used fully both in the regular sector and for the systematic creation of new productive knowledge. $\left(1-v_{n}^{A}\right)$ is the exogenously given share of the labor force in the non-food sector. The growth rate of knowledge thus constant at $\left(1-v^{A}\right)$ and there is no "scale effect" in (8) since the growth rate does not increase with the level of the population. ${ }^{16}$ Again for reasons of simplification, the equation in (8) does not allow for absorption of ideas from other environments. ${ }^{17}$

The previously assumed Malthusian link between technological advance and population growth is still in place, so that the population growth rate is proportional to the growth rate of $A_{n}(t)$.

$$
\frac{\dot{L}_{n}(t)}{L_{n}(t)}=\frac{\dot{A}_{n}(t)}{\alpha A_{n}(t)}=\frac{1-v^{A}}{\alpha}
$$

It also follows from (8)-(9) that steady state output growth in the agricultural economy is $\dot{y}_{n} / y_{n}=\dot{A}_{n} / A_{n}-\alpha \dot{L}_{n} / L_{n}=0$, implying that output per capita stays at subsistence level.

\footnotetext{
${ }^{16}$ See Jones (1999) for an overview of the debate on scale effects in modern growth theory.

${ }^{17}$ For a model that treats the spread of technology explicitly, see for instance Olsson (2000).
} 
The third fundamental stage in economic history is the modern industrial economy. This stage is generally regarded to have been initiated in the Western world by the end of the eighteenth century. Numerous researchers have extensively analyzed the era and a full treatment is beyond the scope of this paper. Here, we will only briefly sketch what we understand to be the main lines of development: An increased rate of endogenous technological progress, the collapse of the Malthusian link between technology (or output) and population, and a rapid rise in standards of living.

In our highly simplified framework, the Industrial Revolution occurs when the technology variable attains the industrial threshold level $A^{I R}$. This happens at time $t_{n}^{I R}$, so that $A^{I R}=A\left(t_{n}^{I R}\right)$. In eighteenth century Britain, the final pieces of technological knowledge, which were in place before the threshold level was reached and development took off, included the insights in atmospheric pressure inherent in the first primitive steam engines of Newcomen and Watt, the principles behind Hargreaves' early spinning jenny and Crompton's mule, and a number of new precision tools such as planing machines and lathes which would be crucial for standardized production (Mokyr, 1990). Standardized production in factories was in itself an organizational innovation that greatly improved efficiency.

Output per capita in the industrial era $\left[t_{n}^{I R}, T\right]$ is given by the production function in (1) with the following specification:

$$
y_{n}(t)>\underline{y}, \quad \delta(t)=\delta^{I R}>\delta^{A}>1, \quad A_{n}(t)>A^{I R}, \quad v(t)=v^{I R}<v^{A}<1 \quad \text { at all } t \in\left(t_{n}^{I R}, T\right]
$$

The new values in (10) are meant to describe a unified agricultural and industrial production process. This new structure of production differs from agricultural production in several respects: Factor productivity has once again made a significant leap $\left(\delta^{I R}>\delta^{A}\right)$ but this time due to organizational innovations and economies of scale, and the intermediate capital goods in the range $A_{n}(t)-A^{I R}>0$ are very different in nature from those in the previous stages. Another important change is that a larger fraction of the labor force is now active in the sector that does not produce physical goods $\left(v^{I R}<v^{A}\right)$. An "R\&D" sector is gradually coming into place which 
together with a growing education sector make up the knowledge producers in the economy. The function describing their creation process is shown in (11).

$$
\dot{A}_{n}(t)=A_{n}(t)\left(1-v^{I R}\right)
$$

Apart from the change in levels of certain parameters, the fundamental difference between the agricultural and the industrial eras concerns the Malthusian link between technological advance and population growth. After the Industrial Revolution the link disappears:

$$
\frac{\dot{L}_{n}(t)}{L_{n}(t)}=\eta \geq 0
$$

$\eta$ is independent of $\dot{A}_{n} / A_{n}$ and assumed to be constant over all $n$.

The reason for this empirical regularity has been widely discussed. In the model by Galor and Weil (2000), technological progress increases the returns to human capital, which eventually results in an endogenous switch from child "quantity" to child "quality". We believe this may be an important reason, although we do not model it explicitly. The assumed rather than derived break of the Malthusian link is admittedly a somewhat crude feature of our model. $^{18}$

The implication of the termination of the Malthusian link is that

$$
\frac{\dot{y}_{n}}{y_{n}}=\frac{\dot{A}_{n}}{A_{n}}-\alpha \frac{\dot{L}_{n}}{L_{n}}=1-v^{I R}-\alpha \eta>0 \quad \text { at all } t \in\left(t_{n}^{I R}, T\right]
$$

Thus, the growth rate of technology finally dominates the growth rate of population, which results in a secular rise in standards of living.

\subsection{Comparative Statics}

\footnotetext{
${ }^{18}$ A richer model, focused on how biogeographic conditions influence population growth, might be an extension of our work.
} 
The sections above show how a favorable biogeography led to an early transition to agriculture. We now demonstrate how these favorable initial conditions also affect contemporary levels of prosperity.

By solving the first-order linear differential equation implicit in (13), it is clear that we can write the current level of output per capita in the $n$-th economy as:

$$
y_{n}(T)=y_{n}\left(t_{n}^{I R}\right) \cdot \exp \left[\left(1-v^{I R}-\alpha \eta\right)\left(T-t_{n}^{I R}\right)\right]
$$

Of the terms in (14), we know from (7) that $y_{n}\left(t_{n}^{I R}\right)=\underline{y}$, that is each economy starts from the same subsistence level at the time its Industrial Revolution occurred. The growth rate after this date $\left(1-v^{A}-\alpha \eta\right)$ is also identical across regions. What differs is the length of time elapsed since the Industrial Revolution, $\left(T-t_{n}^{I R}\right)$. The next step is therefore to attain an expression for $t_{n}^{I R}$. In order to do so, we must first solve the differential equation implicit in (8) to yield the level of productive knowledge at the time of the Industrial Revolution (at time $t=t_{n}^{I R}$ ):

$$
A_{n}\left(t_{n}^{I R}\right) \equiv A^{I R}=A^{A} \cdot \exp \left[\left(1-v^{A}\right)\left(t_{n}^{I R}-t_{n}^{A}\right)\right]
$$

From (15) we can express $t_{n}^{I R}$ as a function of the time of the agricultural revolution $t_{n}^{A}$

$$
t_{n}^{I R}=\frac{\ln A^{I R}-\ln A^{A}}{1-v^{A}}+t_{n}^{A}=\theta+t_{n}^{A}
$$

where recall that we imposed a constant duration for the agricultural era, $\theta$, across environments. The important insight from this result is that, all else equal, the earlier the transition to agricultural production (the smaller the $t_{n}^{A}$ ), the earlier the transition to an industrial economy (the smaller the $\left.t_{n}^{I R}\right){ }^{19}$

\footnotetext{
${ }^{19}$ In the spirit of Brezis et al's (1993) model of leapfrogging technological leadership, a referee remarked that countries without a comparative advantage in agriculture (as opposed to those with one) might have made the earlier transitions to industrial production. We agree that this phenomenon might have been present in Western Europe, but such leapfrogging competition took place between relatively rich countries with a favorable initial biogeography. Sub-Saharan Africa, for instance, endowed with a poor biogeographic potential, did not industrialize before Europe despite its lack of comparative advantage in agriculture.
} 
By taking logs of (14) and substituting in $\underline{y}$ and the expression in (16), we can express the current level of log per capita income at $t=T$ as:

$$
\ln y_{n}(T)=\ln \underline{y}+\left(1-v^{I R}-\alpha \eta\right)\left(T-\theta-t_{n}^{A}\right)
$$

Simple comparative statics of (17a) gives the intuitive result that $\partial \ln y_{n}(T) / \partial t_{n}^{A}=-\left(1-v^{I R}-\alpha \eta\right)<0$. Hence the later was the transition to sedentary agriculture (and, therefore, the later was the onset of sustained technological progress), the lower is the present level of income per person. Log income per capita in all regions increases with time $T$, decreases with $\theta$, and increases with the allocation of labor in the knowledge sector, $\left(1-v^{I R}\right)$. The population growth rate $\eta$ has a negative effect on output per capita.

The dependence of current income on initial biogeographic conditions, however, are the relations we want to emphasize. We know from earlier results that $A_{n}\left(t_{n}^{A}\right)=\exp \left(\gamma \tilde{A}_{n} t_{n}^{A}\right)$ and that $t_{n}^{A}=\ln A^{A} / \gamma \tilde{A}_{n}=\kappa / \tilde{A}_{n}$ (Eq. 5). Writing output per capita as a function of $\tilde{A}_{n}$ instead of $t_{n}^{A}$ yields

$$
\ln y_{n}(T)=\ln \underline{y}+\left(1-v^{I R}-\alpha \eta\right)\left(T-\theta-\frac{\kappa}{\tilde{A}_{n}}\right) .
$$

Equation (17b) establishes the link between present day log income per capita and biogeographic conditions before the agricultural revolution. The key variables in this regard are of course those contributing to $\tilde{A_{n}}$. Differentiation of $\ln y_{n}(T)$ with respect to $\tilde{A_{n}}$ yields $\partial \ln y_{n}(T) / \partial \tilde{A}_{n}=\left(1-v^{I R}-\alpha \eta\right) \cdot \kappa / \tilde{A}_{n}^{2}>0$, that is, current log output per capita increases with the initial productive potential of environment $n$. Note also that the second derivative of $\ln y_{n}^{I R}(T)$ with respect to $\tilde{A}_{n}$ in $(17 \mathrm{~b})$ is negative, implying that the positive relationship between $\ln y_{n}(T)$ and $\tilde{A_{n}}$ is concave.

As pointed out before, a large $\tilde{A}_{n}$ implies a small $t_{n}^{A}$, which in turn implies a small $t_{n}^{I R}$; in other words early transitions to agricultural and industrial production and a long period of endogenous technological progress. Regions with a well endowed natural environment, which 
consequently made the transitions to agriculture and industry comparatively early, should other things equal have higher income per capita today than more poorly endowed regions where the transitions came later. This central implication of the model is evaluated empirically in the next section.

\section{Some Empirical Evidence}

The principal prediction of the theoretical exercises in section three is that contemporary levels of economic development should be positively related to initial biogeographic endowments, that is, to biogeographies favoring an early transition to agriculture. Calibration of initial conditions, $\tilde{A}_{n}$, is necessarily imprecise. However, there are a number of plausible proxies. We use measurements of five key geographic and biogeographic variables: size of continent, major axis of continent, climate (calibrated in two ways), and the number of animal and plant candidates for domestication.

Figure 1: Biogeography and Long-Run Economic Development

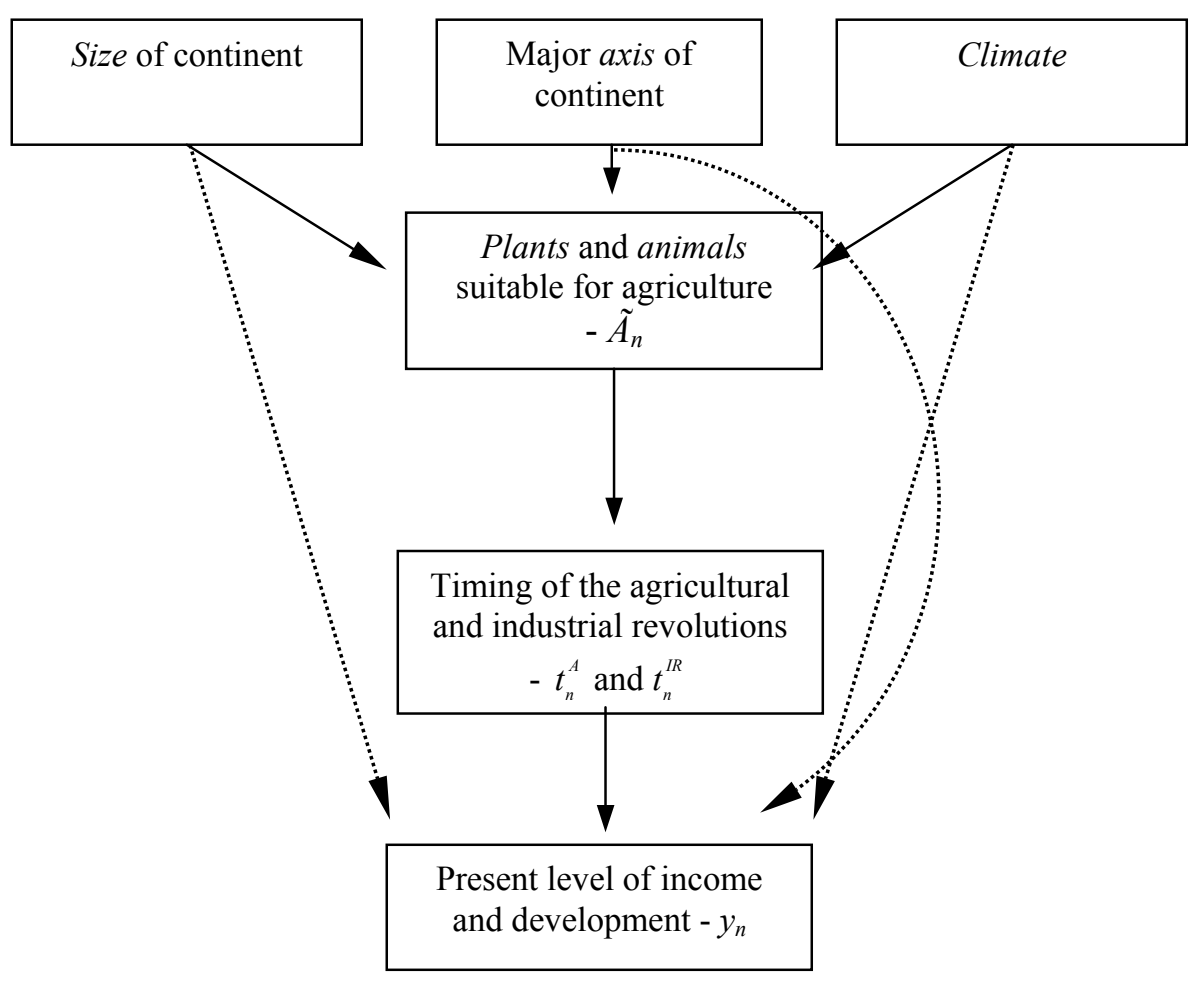

The sequence of relationships is depicted in Figure 1. All else equal, the larger the size of a continent or landmass, the greater the biodiversity and the greater the number of species suitable 
for domestication. The more pronounced the East-West orientation of the major axis, the easier was the diffusion of agricultural innovations between areas. A temperate climate, and in particular the Mediterranean subtype, favors annual grasses like wheat and barley. Geography (inclusive of climate) affects the number of plant and animal species suited to domestication, which in turn determined the timing of the agricultural revolution and the subsequent evolution of endogenously created knowledge and the onset of sustained growth. Yet even after the transition to agriculture, it is likely that the size, axis, and climate of continents continued to exert influence on development. ${ }^{20}$ Greater continental size meant greater population and fiercer competition between societies. An East-West orientation of the landmass continued to facilitate the diffusion of knowledge since transmitters of innovations had to pass through fewer rain forests or deserts. A temperate climate still meant fewer diseases harmful to humans and livestock, rainfall patterns and soil qualities favoring stable growth of nutritious plants, as well as temperatures favoring hard work.

\subsection{Samples and Measurement ${ }^{21}$}

Table 3 reports descriptive statistics on variables appearing in the regressions ahead. We obtained measurement of pertinent variables for the largest possible samples, but excluded (i) countries whose current income per capita is based primarily on extractive wealth (mainly oil production based initially on foreign technology and skilled labor), and (ii) "neo European" countries (Australia, Canada, New Zealand and the United States) where the food and technology package was transferred by European colonizers hundreds of years ago, rather than having developed indigenously. Countries with these characteristics are omitted because our model and principal hypothesis are not germane to the sources of their present prosperity.

The metrics of some of our variables have no natural or intuitive interpretation. Hence to facilitate assessments of relative effects we convert all variables, except output per capita, to 'standard' form, which yields variates with mean zero and unit variance. ${ }^{22}$ Exogenous geographic conditions are measured by four variables: Climate is based on Köppen's system of climatic classification and is distilled from Strahler and Strahler (1992). It takes four discrete

\footnotetext{
${ }^{20}$ The observant reader will note that such a direct influence is not explicitly modeled in the theoretical section. 21 The data series and more detailed definitions of variables can be downloaded from our website: http://www.handels.gu.se/econ/Macroeconomics/rpubs.html.

${ }^{22}$ In standard form (or "z form") a variate $X$ is $X_{-} z=(X-\bar{X}) / \hat{\sigma}_{x}$. Standardization of the regressors of course affects only the scale of slope coefficient estimates facilitating, as noted, comparisons of relative magnitudes (responses of a regressand to standard deviation changes in regressors).
} 
values; with 3 denoting the best climate for agriculture (Mediterranean and West Coast climates) and 0 denoting the worst (tropical dry). Latitude is the distance from the equator in absolute latitude degrees (World Bank, 1999). It captures climatic effects not picked up by the somewhat crude Köppen classification; as noted already low latitudes are associated with poor soil quality, highly variable rainfall and a high incidence of debilitating tropical disease. Axis is a rough measure of the east-west orientation of the major landmasses and is obtained by dividing each continent's distance in longitudinal degrees between the eastern and westernmost points with its north-west distance in latitudinal degrees. As pointed out earlier, it measures barriers to the transmission of goods, people and ideas. Size is the number of square kilometers of the landmass to which each country belongs. As indicated in Table 4, the measures of geography (and biogeography) exhibit fairly high correlations. (Multicollinearity is of course more pronounced than the magnitudes of shared variance implied by the bivariate correlations.) Hence we compute Geo Conditions - the first principal component of the four geographic variables just described. The principal component scores are in standard form with mean zero and unit variance.

Table 3: Statistics

\begin{tabular}{lccccc}
\hline Variable & N Obs & Mean & Std Dev & Minimum & Maximum \\
\hline Climate & 112 & 0 & 1.0 & -1.52 & 1.45 \\
Latitude & 112 & 0 & 1.0 & -1.43 & 2.32 \\
Axis & 112 & 0 & 1.0 & -1.48 & 2.22 \\
Size & 112 & 0 & 1.0 & -1.77 & 1.04 \\
Geo Conditions & 112 & 0 & 1.0 & -1.28 & 1.89 \\
Plants & 112 & 0 & 1.0 & -0.95 & 1.53 \\
Animals & 112 & 0 & 1.0 & -0.91 & 1.28 \\
Bio Conditions & 112 & 0 & 1.0 & -0.97 & 1.39 \\
Political Environment & 102 & 0 & 1.0 & -1.93 & 2.05 \\
Social Infrastructure & 100 & 0 & 1.0 & -1.45 & 2.15 \\
$\begin{array}{l}\text { 1997 GDP } \\
\text { per capita }\end{array}$ & 112 & 4,850 & 5,291 & 369 & 21,974 \\
$\begin{array}{l}\text { log 1997 GDP } \\
\text { per capita }\end{array}$ & 112 & 7.9 & 1.1 & 5.9 & 10.0 \\
\hline
\end{tabular}

Notes: Except for the GDP terms, all variables are in standard form with mean zero and unit variance. Geo Conditions is the first principal component of Climate, Latitude, Axis and Size. Bio Conditions is the first principal component of Plants and Animals. As implied by Table 2, plants, animals and Bio Conditions take only 7 independent variations, not ' $\mathrm{N}$ Obs $=112$ '. 
Initial biogeographic endowments are measured by two variables: Plants is the number of annual or perennial wild grasses with a mean kernel weight exceeding 10 milligrams known to exist in prehistory in various parts of the world. Animals is the number of domesticable mammals weighing more than 45 kilograms known to exist in prehistory in various parts of the world. Both Plants and Animals are based on the information in Table 2. Bio Conditions is the first principal component of these variables; like Geo Conditions it is in standard form with mean zero and unit variance.

Table 4: Correlations

\begin{tabular}{l|cccccccccc} 
Variable & 1 & 2 & 3 & 4 & 5 & 6 & 7 & 8 & 9 & 10 \\
\hline 1 Geo Conditions & 1.0 & & & & & & & & \\
2 Climate & .80 & 1.0 & & & & & & & \\
3 Latitude & .84 & .74 & 1.0 & & & & & & \\
4 Axis & .84 & .48 & .53 & 1.0 & & & & & \\
5 Size & .69 & .30 & .33 & .67 & 1.0 & & & & \\
6 Bio Conditions & .88 & .82 & .78 & .68 & .50 & 1.0 & & & & \\
7 Plants & .84 & .81 & .77 & .60 & .48 & .96 & 1.0 & & & \\
8 Animals & .86 & .77 & .74 & .72 & .49 & .96 & .86 & 1.0 & & \\
9 Political Environment & .68 & .61 & .73 & .49 & .26 & .62 & .57 & .63 & 1.0 & \\
10 Social Infrastructure & .59 & .52 & .60 & .49 & .18 & .56 & .48 & .60 & .87 & 1.0
\end{tabular}

Notes: Geo Conditions is the first principal component of Climate, Latitude, Axis and Size. Bio Conditions is the first principal component of Plants and Animals. All variables are in standard form with mean zero and unit variance; therefore correlations between a principal component and the variables used to generate it are identical to the component's loading factor.

Political Environment and Social Infrastructure are "institutional" variables that geography and biogeography are conditioned on in some of the log output per capita regression experiments. The former is the average of Knack and Keefer's (1995) coding over 1986-95 of five political-institutional characteristics of each country: (i) quality of bureaucracy, (ii) rule of law, (iii) government corruption, (iv) risk of expropriation and (v) risk of government repudiation of contracts. The later variable was developed by Hall and Jones (1999) to quantify the wedge between social and private returns to productive activity; it is the average of Knack and Keefer's political codings and Sachs and Warner's (1995) index of the openness of each 
country to free trade during 1950 to 1994. Finally, 1997 GDP per capita is expressed in constant US dollars at base year 1985 international prices (World Bank, 1999).

\subsection{Regressions}

Tables 5 and 6 report evidence from regressions. The regression setups are far from perfect representations of the equations presented in section three, which themselves are merely stylized mechanisms designed to aid thinking about the connections of geography and biogeography to contemporary levels of economic development. Regressions 1 to 4 in Table 5 pertain to the first link of the long-run causal scheme featured in our historical analysis and illustrated by Figure 1. These regression experiments show that exogenous geographic conditions explain around 80 percent of the variance of the international distribution of heavy seeded plants and large domesticable animals that are known to have existed in prehistory. ${ }^{23}$

Regression 5 pertains to the second link in the long-run causal chain: The influence of initial biogeographic endowments on the timing of the transition to sedentary agriculture, which we regard as one of the most important events in the thousands of years of humankind's economic development. The transition dates are based on calibrated radiocarbon dating of the first domestication of any plant or animal, with the first transition occurring approximately 10,500 years ago (8500 B.C. in the Near East) and the most recent around 4,500 years ago (2500 B.C. in North America). ${ }^{24}$ Such information is available for 8 regions of the world. This limited body of data nonetheless supports the thesis that the richer was a region's initial biogeographic endowment, the earlier was the transition out of hunter-gatherer production to agriculture. The composite Bio Conditions variable explains 67 percent of the variance in calibrations of the number of years since the transition to agricultural production $\left(T-t_{n}^{A}\right)$, and it shows some sign of the concavity implied by Eq. (5).

\footnotetext{
${ }^{23}$ As mentoned earlier note that Plants, Animals and Bio Conditions do not take $\mathrm{N}=112$ independent variations. The composite Bio Conditions variable takes just 7 variations over the $\mathrm{N}=112$ countries.

${ }^{24}$ See Diamond (1997) and Smith (1998). The 8 regions include the six independent origins of agriculture in Table 1, plus Australia and the Pacific where agriculture was never independently developed.
} 
Table 5: Regressions for Initial Bio Conditions, $\tilde{A}_{n}$, and Years Since Transition to Sedentary Agriculture, $\left(T-t_{n}^{A}\right)$

\begin{tabular}{|c|c|c|c|c|c|}
\hline & $\begin{array}{l}\text { Plants } \\
\text { (1) }\end{array}$ & $\begin{array}{c}\text { Animals } \\
\text { (2) }\end{array}$ & $\begin{array}{c}\text { Bio Conditions } \\
\text { (3) } \\
\end{array}$ & $\begin{array}{c}\text { Bio Conditions } \\
\text { (4) }\end{array}$ & $\begin{array}{c}\text { Years Since } \\
\text { Transition to } \\
\text { Agriculture } \\
(5)\end{array}$ \\
\hline Climate & $\begin{array}{c}0.50 \\
(7.2 \mid .00)\end{array}$ & $\begin{array}{c}0.42 \\
(6.1 \mid .00)\end{array}$ & $\begin{array}{c}0.47 \\
(7.8 \mid .00)\end{array}$ & & \\
\hline Latitude & $\begin{array}{c}0.31 \\
(4.3 \mid .00)\end{array}$ & $\begin{array}{c}0.21 \\
(2.9 \mid .00)\end{array}$ & $\begin{array}{c}0.26 \\
(4.2 \mid .00)\end{array}$ & & \\
\hline Axis & $\begin{array}{c}0.08 \\
(1.1 \mid .26)\end{array}$ & $\begin{array}{c}0.37 \\
(5.36 \mid .00)\end{array}$ & $\begin{array}{c}0.23 \\
(3.8 \mid .00)\end{array}$ & & \\
\hline Size & $\begin{array}{c}0.17 \\
(2.8 \mid .00)\end{array}$ & $\begin{array}{c}0.04 \\
(0.65 \mid .50)\end{array}$ & $\begin{array}{c}0.11 \\
(2.0 \mid .05)\end{array}$ & & \\
\hline Geo Conditions & & & & $\begin{array}{c}0.83 \\
(19.8 \mid .00)\end{array}$ & \\
\hline Bio Conditions & & & & & $\begin{array}{c}6,458 \\
(3.1 \mid .02)\end{array}$ \\
\hline $\begin{array}{l}\text { Bio Conditions } \\
\text { Squared }\end{array}$ & & & & & $\begin{array}{c}-2,281 \\
(-1.8 \mid .13)\end{array}$ \\
\hline $\begin{array}{l}\text { Adjusted } \\
\text { R-Squared }\end{array}$ & .77 & .76 & .81 & .78 & .67 \\
\hline St. Error & 0.48 & 0.49 & 0.42 & 0.46 & 2,196 \\
\hline $\mathrm{N}$ & 112 & 112 & 112 & 112 & 8 (regions) \\
\hline
\end{tabular}

Notes: In parentheses are t-ratios | significance levels (p-values). Regression constants are omitted.

Table 6 reports regressions for log 1997 GDP per capita, the end-point of the long causal sequence depicted in Figure 1. International variation in contemporary per capita incomes is truly staggering. Across the 112 countries in our biggest sample, 1997 GDP per capita expressed in 1985 US dollars ranges from 369 (Ethiopia) to 21,974 (Luxembourg) -- a nearly sixty-fold difference. The first three regression experiments indicate that geography and biogeography are able to account for between 40 and 50 percent of the variance in $1997 \log$ incomes per capita. Our crude measurement of biogeographic endowments fits almost 40 percent of the international variation all by itself, and reveals some signs of the concave effects implied by Equation 10b (the quadratic Bio Conditions term in Regressions 2 and 3). ${ }^{25}$ In view

\footnotetext{
${ }^{25}$ In the smaller samples $(\mathrm{N}=100, \mathrm{~N}=102)$ corresponding to the empirical base for regressions 4-9, Geo and Bio Conditions fit 50 percent of the 1997 international variation in log output per capita.
} 
of the fact that we have only seven independent variations of prehistoric Bio Conditions (Plants and Animals) in the 112-country sample (cf. Table 2), we take this to be a quite remarkable result.

Table 6: Regressions for $1997 \log$ GDP per capita

(1) (2)

0.35

$(3.1 \mid .00)$

Axis

0.17

$(1.8 \mid .07)$

Latitude

0.40

$(3.4 \mid 00)$

\section{Geo Conditions}

Bio Conditions

Bio Conditions

Squared

Political

Environment

Social

Infrastructure

.49

.38

\subsection{2}

$(2.5 \mid .01)$

$0.88 \quad 0.48$

$(6.3 \mid .00) \quad(2.2 \mid .02)$

$\begin{array}{ll}-0.32 & -0.31\end{array}$

$(-1.6 \mid .11) \quad(-1.6 \mid .11)$

\author{
(4)
}

(5)

(6)

(7)

(8)

\begin{tabular}{lccccccccc} 
Adjusted & .49 & .38 & .41 & .66 & .69 & .69 & .71 & .77 & .76 \\
R-Squared & & & & & & & & & \\
St. Error & 0.80 & 0.88 & 0.86 & 0.68 & 0.65 & 0.65 & 0.63 & 0.57 & 0.58 \\
$\mathrm{~N}$ & 112 & 112 & 112 & 102 & 102 & 102 & 100 & 100 & 100 \\
\hline
\end{tabular}

Notes: In parentheses are t-ratios | significance levels (p-values). Regression constants are omitted.

Yet the evidence in regressions 1 to 3 in Table 6 should not be over interpreted. For example, taken at face value the estimates for regression 3 imply that a change from the worst Bio and Geo Conditions to the best would yield a shift in 1997 GDP per capita from around 1,000 dollars to around 8,600 dollars. ${ }^{26}$ Given measurement imprecision, exogenous geography and initial condition biogeography therefore are able to account for at least eight and one-half of

\footnotetext{
${ }^{26}$ These estimates are computed straightforwardly by applying the coefficients in regression 3, Table 6 (along with the omitted constant) to the range of variation (reported in Table 3) of Geo and Bio Conditions, and then finding the implied levels of GDP per capita from the predicted log values.
} 
the nearly sixty-fold difference in contemporary incomes per head which is observed in a broad international cross-section of countries. This corresponds to the development gaps between, for instance, Ghana, Nigeria or Zimbabwe (where incomes are in the vicinity of 1000 dollars of income per head) and Greece, Malaysia or Portugal (where incomes lie in the interval 7,300 to 8,700 dollars per head).

The full range of international variation in incomes per person, however, runs from the 400 to 500 dollars per person typical of the poorest countries to the 15,000 to 20,000 dollars per person enjoyed by the richest. Hence, a complete accounting of contemporary variations in economic prosperity requires explanatory variables generating predictions that halve the per capita incomes implied by the worst geography and biogeography, and that double the per capita incomes implied by best. The leading candidates are the political and institutional arrangements that constrain, and at times influence decisively, the effectiveness of economic activity.

Regressions 4 to 9 report the effects of the Political Environment and the Social Infrastructure variables introduced earlier and featured in the studies by Acemoglu et al. (2001) and Hall and Jones (1999), respectively. The estimates from these regressions reinforce the results of these and many other studies indicating that the quality of political-institutional arrangements has potent statistical influence on per capita output levels (and growth rates) recorded across countries. ${ }^{27}$

Although political and institutional arrangements clearly have proximate, statistically powerful effect on economic performance, regressions 5, 6, 8 and 9 demonstrate that Bio Conditions and Geo Conditions retain significance and substantive importance in the presence of the former variables. Moreover, every one of our measures of geography is truly exogenous unlike, for example, many of the geography variables featured in the papers of Gallup et al. 1999 and Sachs and Warner, 1997, among others. And our measurements of biogeographic initial conditions (Plants, Animals and their first principal component, Bio Conditions) are dated, in most recent vintage, from approximately 4,500 years ago. Even though endogenous in our very long-run historical causal sequence (Figure 1), biogeography is indisputably exogenous with respect to current incomes. Problems of joint endogeneity and reverse causation are therefore decisively ruled out in our theoretical setups and in our empirical estimates of the effects of geography and biogeography on present day levels of economic development.

\footnotetext{
${ }^{27}$ Hibbs (2001) supplies analysis of some recent studies along with discussion of the gradual detachment of empirical models of growth and development from traditional neoclassical theory and, in fact, from any formal theory of economic growth in mainstream economics.
} 
The same is not true, however, of the political-institutional variables; among other reasons because rich countries have the resources to build institutions of high quality. Researchers have struggled with the joint endogeneity issue, proposing various instrumental variables to obtain consistent estimates of the proximate effects of politics and institutions on economic performance, along with the related question of how much influence, if any, natural endowments exert on economic development independent of institutional development. None of these attempts is entirely persuasive in our view. ${ }^{28}$ If our theoretical model and empirical results are to be believed, geographic and biogeographic variables are invalid instruments for politics and institutions because of the strong direct effects of Geo and Bio Conditions on contemporary per capita incomes registered by our regressions, even when biogeography is conditioned on institutional variables.

Indeed, we are tempted to model political-institutional arrangements affecting economic prosperity as an intervening variable(s) driven at least to some degree by the same geographic and biogeographic variables that are the first movers of the timing of the transition to agriculture and the onset of sustained positive growth. ${ }^{29}$ Regressing the Political Environment variable on Geo Conditions and Bio Conditions (with $t$-ratios and $p$-values in parentheses as before) we obtain :

$$
\begin{aligned}
& \text { Political Environment }=0.669 \text { Geo Conditions }, \quad R^{2}=.45(N=102) \\
& (9.2 \mid .00) \\
& \text { Political Environment }=\underset{(7.81 .00)}{0.639} \text { Bio Conditions, } \quad R^{2}=.37 \quad(N=100)
\end{aligned}
$$

These regressions notwithstanding, we believe along with many others that the politicalinstitutional environment has powerful and genuinely independent causal effect on economic growth and development. Yet because of difficult to resolve identification problems, just how big an influence politics and institutions exert on economic performance has in our view not

\footnotetext{
${ }^{28}$ As an illustration, take the Hall and Jones (1999) study which uses latitude, the fraction of the population speaking English and the fraction speaking another European language as instruments for Social Infrastructure. However, a high incidence of English and other European languages in current periods is strongly associated with non-extractive colonization (what Acemoglu et al., 2000, call the creation of "neo Europes"), which meant the wholesale transference of an advanced food and technology package from the most advanced societies of the time to the new worlds that most likely still affects development levels. Latitude is even more difficult to defend as a legitimate instrument. The unstable rainfall, poor soil quality and prevalence of disease associated with the lower latitudes almost surely depresses economic development directly, as Gallup, Sachs and Mellinger (1999), for example, have forcefully argued.

${ }^{29}$ This line of reasoning is the centerpiece of Easterly and Levine (2002) and is featured also in Acemoglu et al. (2001) and Acemoglu et al. (2002).
} 
been pinned down with great precision. ${ }^{30}$ Unlike equations specified with geography and biogeography alone, regressions like 5, 6, 8 and 9 that include political-institutional variables explain the lion's share of cross-national variance in log output per capita, with $R^{2} s$ running from .75 to .80 . More pragmatically, these models yield fits that come much closer to spanning the full dispersion of per capita incomes observed internationally. Applying the estimates from regression 6, for instance, we calculate that the incomes per person associated with the worst and best combinations of Bio Conditions and Political Environment are around 600 dollars and 13,700 dollars, respectively.

\section{Concluding Summary}

Archaeological and related evidence strongly suggests that the timing and location of transitions from hunting and gathering to horticulture and animal husbandry were decisively affected by the biogeographic endowments of various regions of the world in prehistory. This historical observation is a key feature of our stylized model of economic growth and development. In our model biogeographic productive potentials drive transitions to sedentary agriculture, which in turn make possible the formation of a non-food producing class of knowledge creators whose activities fuel endogenous technological progress and rapid population growth. Due to Malthusian forces, output per capita remains at subsistence level until the industrial stage is reached. The model implies that the earlier the transition from hunter-gatherer to agricultural production, the longer the period of endogenous growth of knowledge, the earlier the transition to industrial production, and the higher the level of economic development - even in the present day.

The main implications of our reading of history and of our theoretical setup received quite strong support in the data. Consistent with the long-run causal scheme depicted in Figure 1, we found that measures of exogenous geographic conditions explain more than three-quarters of the regional variation in prehistoric biogeography. As implied by our theoretical model, these admittedly rough measurements of biogeography are positively (and perhaps concavely) related to our equally rough assessments of the transition dates to sedentary

\footnotetext{
${ }^{30}$ For an early attempt to sort out in a large cross-section of countries the complex joint endogeneities among many of the variables appearing in the new political economy of growth and development literature institutional and democratic political development, political violence and civil war, ethnolinguistic fractionalization, social mobilization and more - see Hibbs (1973).
} 
agriculture; our Bio Conditions variable accounts for around two-thirds of the regional variation in the estimated dates of transition.

Our empirical analyses, however, focused principally on contemporary levels of economic development. Our regressions showed that as much as half of the 1997 international variation in log output per person can be explained by our noisy measures of exogenous geography and prehistoric biogeography. We interpreted this regression evidence to give remarkably strong support to a central prediction of our theoretical model and the associated historical analysis: Current variations in economic prosperity to a significant degree still embody the effects of the prehistoric productive potentials of various environments. Moreover, the geographic and biogeographic signals we detected in current levels of income per person were robust to controls for political and institutional variables that are known to exert powerful, proximate statistical influence on international variations in economic prosperity.

\section{References}

Acemoglu, D. and S. Johnson and J. Robinson (2001), “The Colonial Origins of Comparative Development: An Empirical Investigation”, American Economic Review 91(5): 1369-1401.

Acemoglu, D. and S. Johnson and J. Robinson (2002), "Reversal of Fortunes: Geography and Institutions in the Making of the Modern World Income Distribution” forthcoming Quarterly Journal of Economics.

Bloom, D. and J. Sachs (1998) “Geography, Demography and Economic Growth in Africa” Brookings Papers on Economic Activity 1998(2): 207-295.

Blumler, M. (1992) Seed Weight and Environment in Mediterranean-type Grasslands in California and Israel. PhD-dissertation, UC Berkeley, Ann Arbor: UMI Dissertation Services.

Boserup, E. (1965) The Conditions of Agricultural Growth. London: Earthscan.

Brezis, E.S., P. Krugman and D. Tsiddon (1993) "Leapfrogging in International Competition: A Theory of Cycles in National Technological Leadership" American Economic Review 83(5): 1211-1219.

Childe, V.G. (1935) New Light on the Most Ancient East. London: Routledge.

Cohen, M.N. (1977) The Food Crises in Prehistory: Overpopulation and the Origins of Agriculture. New Haven: Yale University Press.

Cohen, M.N. and G.J. Armelagos (1984) Paleopathology at the Origins of Agriculture. New York: Academic Press.

DeLong, J.B. (1998) "Estimating World GDP, One Million B.C. - Present" Website document at http://econ161.berkeley.edu/TCEH/2000/World_GDP/Estimating_World_GDP.htm

Diamond, J. (1997) Guns, Germs and Steel: The Fates of Human Societies. New York: Norton.

Easterly, W. and R. Levine (2002) "Tropics, Germs, and Crops: How Endowments Influence Economic Development", mimeo.

Fernandez-Armesto, F. (2000) Civilizations. London: MacMillan.

Fogel, R.J. (1999) "Catching Up with the Economy" American Economic Review 89(1): 1-22. 
Gallup, J.L. and J.D. Sachs and A.D. Mellinger (1999) “Geography and Economic Development" International Regional Science Review 22(2): 179-232.

Galor, O. and D. Weil (2000) "Population, Technology, and Growth: From the Malthusian Regime to the Demographic Transition and Beyond" American Economic Review 90(4): 806-828.

Galor, O. and O. Moav (2002) "Natural Selection and the Origin of Economic Growth" forthcoming.

Goodfriend, M. and J. McDermott (1995) “Early Development” American Economic Review 85:116-133.

Hall, R. and C. Jones (1999) “Why Do Some Countries Produce So Much More Output Than Others?” Quarterly Journal of Economics 114(1): 83-116.

Hansen, G.D. and E. Prescott (1999) "Malthus to Solow" Research Department Staff Report 257, Federal Reserve Bank of Minneapolis.

Hibbs, D.A. (2001) “The Politicization of Growth Theory” Kyklos 54: 265-286.

Hibbs, D.A. (1973) Mass Political Violence. New York: John Wiley and Sons.

Harlan, J. (1995) The Living Fields: Our Agricultural Heritage. Cambridge University Press.

Johnson, D.G. (2000), "Population, Food and Knowledge” American Economic Review 90 (1): 1-14.

Jones, C. (2001) "Was An Industrial Revolution Inevitable?: Economic Growth Over the Very Long Run" Advances in Macreconomics 1(2), <www.bepress.com/bejm/advances>.

Jones, C. (1999) "Growth: With or Without Scale Effects?" AER Papers and Proceedings 89(2): 139-145.

Kamarck, A. M. (1976) The Tropics and Economic Development. Baltimore: John Hopkins University Press.

Knack, S. and P. Keefer (1995) "Institutions and Economic Performance: Cross-Country Tests Using Alternative Institutional Measures” Economics and Politics 7(3): 207-225.

Kremer, M. (1993) “Population Growth and Technological Change: One Million B.C. to 1990" Quarterly Journal of Economics 108(3): 681-716.

Kögel, T. and A. Prskawetz (2001) "Agricultural Productivity Growth and Escape from the Malthusian Trap" Journal of Economic Growth 6: 337-357.

Lagerlöf, N.P. (2000) “From Malthus to Modern Growth: The Three Regimes Revisited” mimeo.

Landes, D. (1998) The Wealth and Poverty of Nations: Why Some Are So Rich and Some So Poor. New York: WW Norton.

Maddison, A. (1982) Phases of Capitalist Development. Oxford University Press.

Masters, W.A. and M.S. McMillan (2001) "Climate and Scale in Economic Growth" Journal of Economic Growth 6: 167-186.

Mokyr, J. (1990) The Lever of Riches. Oxford: Oxford University Press.

Montesquieu, C. L. (1750) The Spirit of Laws. Anne Cohler (ed) (1989). Cambridge University Press.

Morand, O.F. (2001) "Population, Technology and Growth" mimeo.

North, D. (1981) Structure and Change in Economic History. New York: W.W. Norton \& Co.

Nowak, R. (1991)(ed.) Walker's Mammals of the World. Baltimore: John Hopkins University Press.

Olsson, O. (2000) “Knowledge as a Set in Idea Space: An Epistemological View on Growth" Journal of Economic Growth 5(3): 253-276.

Olsson, O. (2001) “The Rise of Neolithic Agriculture” Working Papers in Economics, No 57, Göteborg University

Renfrew, C. (1992) "World languages and human dispersals: a minimalist view" in J.A. Hale and I.C. Jarvie (eds.), Transition to Modernity. Essays on Power, Wealth and Belief. Cambridge: Cambridge University Press, 11-68.

Renfrew, C. (1993) The Roots of Ethnicity, Archaeology, Genetics and The Origins of Europe. Rome: Unione Internazionale Degli Istituti Di Archeologia Storia E Storia Dell'Arte.

Renfrew, C. (1996) "Language families and the spread of farming" in D. Harris (ed.) The Origins and Spread of Agriculture and Pastoralism in Eurasia London: UCL Press. 
Romer, P. (1990) "Endogenous Technological Change” Journal of Political Economy 98:71-102.

Sachs, J. and A. Warner (1995) "Economic Reform and the Process of Global Integration" Brookings Papers on Economic Activity, 1, 1-95.

Sachs, J. and A. Warner (1997) "Fundamental Sources of Long-Run Growth" AER Papers and Proceedings 87(2): 184-188.

Sachs, J. (2001) "Tropical Underdevelopment” NBER Working Paper 8119.

Sala-i-Martin, X. (1997) “I Just Ran Two Million Regressions” AER Papers and Proceedings 87(2): 178-183.

Smith, V. (1975) "The Economics of the Primitive Hunter Culture, Pleistocene Extinctions, and the Rise of Agriculture" Journal of Political Economy 84(4): 727-756.

Smith, B. D. (1998) The Emergence of Agriculture. New York: Scientific American Library.

Strahler, A.H. and Strahler A.N. (1992) Modern Physical Geography. New York: John Wiley and Sons.

World Bank (1999), "Global Development Network Growth Database”. <http://www.worldbank.org/html/prdmg /grthweb/GDNdata.htm>. 